\title{
A PERCEPÇÃO dAS PESSOAS EM RELAÇÃO À GESTÃO DO LIXO DOMICILIAR, COLETA SELETIVA, MATERIAIS REUTILIZÁVEIS E SUSTENTABILIDADE AMBIENTAL.
}

\author{
B.B. Arantes ${ }^{1,}$; R.C.R.L. Maurício ${ }^{1}$; R.A. Moura ${ }^{1}$; V.J. Sousa ${ }^{1}$ \\ 1 Faculdade de Tecnologia de São José dos Campos - Professor Jessen Vidal \\ Av. Cesare Mansueto Giulio Lattes, 1350 - Eugênio de Melo, São José dos Campos/SP, \\ CEP.: 12247-014, Brasil, Telefone: (12) 3905-2423 \\ * brunaarantes14@gmail.com
}

\begin{abstract}
RESUMO: Este trabalho tem como objetivo expor os impactos da coleta seletiva e logística reversa a fim de conscientizar a população sobre a necessidade de um desenvolvimento sustentável. Desta forma, foi feito um estudo sobre a percepção das pessoas referente à destinação dos resíduos sólidos, buscando meios de reflexão quanto à real necessidade de consumir e praticar a separação correta dos lixos juntamente com a quantidade e qualidade de lixo produzido e como se livrar dele. Para tanto, foi utilizada uma pesquisa qualitativa e exploratória da literatura e, através de mídia digital, uma pesquisa quantitativa com 335 voluntários que responderam um questionário sobre a coleta seletiva e afim de obter um diagnóstico da situação. Como resultado percebe-se que a logística reversa do resíduo domiciliar, além de ecologicamente correta, pode trazer mais qualidade de vida para as pessoas. Conclui-se que é necessária uma reeducação ambiental na sociedade em geral.
\end{abstract}

PALAVRAS-CHAVE: Logística Reversa, Sustentabilidade, Coleta Seletiva, Lixo Doméstico.

\begin{abstract}
This paper aims to expose the impacts of selective collection and reverse logistics in order to raise awareness of the need for sustainable development. Thus, a study was made on the perception of people regarding the destination of solid waste, seeking ways of reflection on the real need to consume and practice the correct separation of waste along with the amount and quality of waste produced and how to get rid of it. For this, a qualitative and exploratory research of literature was used and through digital media, a quantitative research with 335 volunteers who answered a questionnaire about the selective collection in order to obtain a diagnosis of the situation. As a result, it is clear that the reverse logistics of household waste, besides being ecologically correct, can bring more quality of life for people. It is concluded that an environmental reeducation is necessary in society in general.
\end{abstract}

KEYWORDS: Reverse Logistics; Sustainability; Selective Collection, Domestic Waste.

\section{INTRODUÇÃO}

Nos dias de hoje ocorrem muitos problemas justamente pelo descarte incorreto dos resíduos, a começar pelo lixo doméstico, percebe-se que como não se pode deixar o lixo acumular dentro das residências, é necessário o descarte, mas é preciso conter a geração de resíduos e dar um tratamento adequado para o lixo, pois a população têm uma percepção errada sobre o assunto e não tem noção da dimensão do problema, por esse motivo o meio ambiente vem sendo degradado dia após dia de 
forma constante. Macedo (2000), evidencia que é por meio da percepção ambiental que se pode atribuir valores e importâncias diferenciadas ao meio ambiente.

Nesta mesma percepção, Zanta e Ferreira (2003), falam que os resíduos domésticos geram grandes problemas e afetam a qualidade de vida de muitas pessoas e o meio onde vivem, mas isso pode servir de oportunidade para a conscientização num modo geral sobre sustentabilidade.

E para conceituar melhor sobre resíduos sólidos (BRASIL, 2012), considera que os resíduos sólidos domiciliares surgem de atividades domésticas em residências urbanas, e que os mesmos são compostos em resíduos secos e molhados.

Diante deste contexto, percebe-se que gerenciar melhor os resíduos domiciliares, além de ecologicamente correto, pode trazer mais qualidade de vida para as pessoas e para que isso seja realmente efetivado é necessário palestras e campanhas, os órgãos governamentais propõem as pessoas o reaproveitamento de seus produtos, o que era lixo agora pode virar matéria-prima retornando o lixo domiciliar para os centros reprodutivos, conceito esse, que vem crescendo nos últimos anos, com o objetivo de sustentabilidade ambiental (GRANDELLE, 2014).

Segundo Paoleschi (2010), a necessidade da logística reversa também provem das Legislações que proíbem o descarte indiscriminado de resíduos no meio ambiente e incentivam a reciclagem de recipientes de bebidas e materiais de embalagem.

Outra forma de descarte consciente é o utilizado na coleta seletiva, pois contribui para que os resíduos tenham um destino adequado, como os materiais recicláveis para que possam ser reutilizados, os orgânicos possam ser transformados em fertilizantes, e assim além de preservar o meio ambiente ajudar nas plantações. Em função do contexto de importância apresentado, este trabalho teve como principal objetivo a análise de conceitos e conscientização sobre a necessidade da coleta seletiva e logística reversa do lixo domiciliar.

\section{REVISÃO DA LITERATURA}

Embora o governo tenha criado diversas políticas sobre o descarte do lixo urbano, mais de $40 \%$ do lixo continua sendo descartado incorretamente. $O$ descarte inadequado de resíduos sólidos provoca danos ao meio ambiente, aos animais e a vida das pessoas. Uma alternativa seria reduzir a geração desses resíduos, e para isso deveriam ser seguidos alguns procedimentos: reduzir o uso de materiais não recicláveis, substituir materiais descartáveis por materiais mais duráveis ou reutilizáveis e diminuir embalagens (MOURA, 2011).

\subsection{Necessidade de um caminho sustentável}

As pessoas devem levar em conta a degradação ambiental, associando às questões econômicas e social, e para isso um dos caminhos que a logística propõe é a logística reversa do lixo gerado.

Os recursos naturais são limitados, sabendo disso, a população deve atentar-se em analisar e sempre estudar alternativas para que impacte da menor maneira possível o meio ambiente já que os danos causados, são por sua vez irreparáveis, pois a cada dia descarta-se mais produtos, por terem sua vida útil curta, devido a contínua mudança de tecnologia.

Através da reciclagem, da reutilização e redução dos materiais usados, as pessoas tornam-se cada vez mais ecológicas e mais eficientes, isso ocorre quando controlam a quantidade e destinam de forma correta dos resíduos (BRAGA e RIZZO, 2010).

É necessário reformular a maneira de enxergar o lixo como algo que pode ser transformado e modificado em uma nova matéria-prima e não como um "resto inútil" gerado no dia-a-dia sem se importar com a sua reutilização.

\subsection{Resíduos sólidos: caracterização e tipos de coleta}


Os resíduos sólidos são qualquer tipo de material, que normalmente são considerados como lixo, substância ou item descartado, por ações humanas e animais ou por consequências de acontecimentos naturais, e podem se apresentar nos estados sólido e semissólido, incluindo os particulados, como é definido no Capítulo I, Art. $2^{\circ}$, o Relatório Preliminar da Política Nacional de Resíduos Sólidos.

A classificação dos resíduos é realizada conforme a sua origem e pode ter diversas formas de classificação, está demonstrada na Tabela 1 (LIMA, 1991).

Tabela 1. Classificação dos resíduos conforme sua origem

\begin{tabular}{|c|c|}
\hline $\begin{array}{l}\text { - Resíduos } \\
\text { Domiciliar }\end{array}$ & $\begin{array}{l}\text { São sobras ou restos de alimentos, vidros, metais, papéis, plásticos dentre outras coisas. São resíduos } \\
\text { mais variados em menos específicos, com mais possibilidade de reciclagem. São gerados em } \\
\text { residências, escritórios, refeitórios etc. }\end{array}$ \\
\hline $\begin{array}{l}\text { - Resíduos } \\
\text { Industriais }\end{array}$ & $\begin{array}{l}\text { Decorrente de fábricas, usinas. São restos de materiais, lodos, subprodutos dos processos de } \\
\text { fabricação, dentre outros. São resíduos mais específicos e menos variado, com potencialidade de } \\
\text { reciclagem. }\end{array}$ \\
\hline $\begin{array}{l}\text { - Resíduos } \\
\text { Comercial }\end{array}$ & $\begin{array}{l}\text { Proveniente de estabelecimentos comerciais, composto basicamente dos mesmos resíduos que o } \\
\text { "Resíduo Domiciliar". É um tipo de resíduo menos específico e mais variado, com capacidade de } \\
\text { reciclagem. }\end{array}$ \\
\hline $\begin{array}{l}\text { - Resíd } \\
\text { Hospit }\end{array}$ & $\begin{array}{l}\text { Gerado por hospitais, farmácias, ambulatórios médicos e clínicas veterinárias. É um tipo de resíduo } \\
\text { mais específico e menos variado, com baixa possibilidade de reciclagem. }\end{array}$ \\
\hline $\begin{array}{l}\text { - Resíduos de } \\
\text { Vias Públicas }\end{array}$ & $\begin{array}{l}\text { Resultado da varrição de ruas, limpeza de bueiros, bocas-de-lobo, canais, terrenos baldios etc. É } \\
\text { composto por terra, folhas, entulhos, detritos diversos, galhos, dentre outros. Possui pouco potencial } \\
\text { de reciclagem. }\end{array}$ \\
\hline $\begin{array}{l}\text { - Entulho da } \\
\text { Construção } \\
\text { Civil }\end{array}$ & $\begin{array}{l}\text { Gerado na construção e reforma de obras particulares, públicas, industriais e comerciais. São por } \\
\text { restos de demolições e sobras de materiais de construção. É um tipo de resíduo mais específico e } \\
\text { menos variado, com potencialidade de reciclagem. }\end{array}$ \\
\hline - Outro & $\begin{array}{l}\text { Proveniente de portos, aeroportos, penitenciárias além daqueles de origens diversas tais como: } \\
\text { produtos resultantes de acidentes, animais mortos, veículos abandonados, dentre outros. }\end{array}$ \\
\hline
\end{tabular}

A Política Nacional de Resíduos Sólidos no Capítulo I, Art. $3^{\circ}$ estabelece que os resíduos sólidos, sejam classificados e se dividam conforme Tabela 2.

Tabela 2. Classificação dos resíduos sólidos

\begin{tabular}{|l||ll|}
\hline \multicolumn{1}{|l||}{$\begin{array}{l}\text { I - Resíduos Comuns: Consistentes } \\
\text { em: }\end{array}$} & a) $\begin{array}{l}\text { Resíduos Urbanos: Resíduos provenientes de } \\
\text { residências ou de qualquer outra atividade que gere } \\
\text { resíduos com características domiciliares ou a estes } \\
\text { equiparados, bem como os resíduos de limpeza } \\
\text { pública urbana. }\end{array}$ \\
\hline \hline & & \\
& a) Resíduos Industriais; \\
& b) Resíduos Minerais; \\
II - Resíduos Especiais: São aqueles & c) Resíduos Radioativos; \\
que necessitam de gerenciamento & e) Resíduos da Construção Civil; \\
específico, em razão de sua tipologia & f) Resíduos Tecnológicos; \\
e/ou quantidade, subdivididos em: & g) Resíduos de Pneumáticos; \\
& h) Resíduos de Explosivos e Armamentos; \\
& i) Resíduos de Embalagens; \\
& j) Resíduos Perigosos; \\
& k) Lodo de Esgoto. \\
\hline
\end{tabular}

\subsection{Coleta Seletiva}


Conforme o Relatório Preliminar da Política Nacional de Resíduos Sólidos define a coleta seletiva como o recolhimento diferenciado de resíduos sólidos previamente selecionados nas fontes geradoras, com o intuito de encaminhá-los para reciclagem, compostagem, reuso, tratamento e outras destinações alternativas, como aterros, coprocessamento e incineração (BRASIL, 2010).

Essa separação propicia a reciclagem dos materiais, pois estando mais limpos, têm maior potencial de reaproveitamento e comercialização (IBGE, 2008).

Portanto qualquer coleta que faz uma breve separação de produto, considera-se uma coleta seletiva (LEITE, 2009).

A coleta seletiva nos bairros é feita através do sistema porta a porta, sendo que os moradores devem separar os materiais recicláveis e colocarem na calçada para serem recolhidos por coletores de lixo em caminhões compactadores em dias específicos, conforme Figura 1, os resíduos são coletados em média seis vezes por semana conforme a densidade demográfica e o volume de materiais gerados em cada bairro ou região, dos quais desses seis dias de coleta três dias são coletados lixos orgânicos, que incluem restos de comidas, folhas de árvores e materiais que não são possíveis reciclar, esses por sua vez são todos encaminhados ao Aterro Sanitário de resíduos sólidos urbanos (ABNT NBR 8419 / 1992), esta é uma técnica de disposição de resíduos sólidos urbanos no solo, sem causar danos à saúde pública e à sua segurança, minimizando os impactos ambientais. Nos outros três dias são coletados lixos recicláveis que neles estão inclusos papéis, vidros, plásticos, metal e isopor, esse tipo de coleta é muito importante porque poderia evitar o uso do aterro sanitário, já que os materiais recicláveis passam pela triagem, onde são separados manualmente por tipo, através uma Central de Cooperativa de Catadores, que comercializam e com isso geram trabalho e renda para diversas famílias, promovendo uma inclusão social.

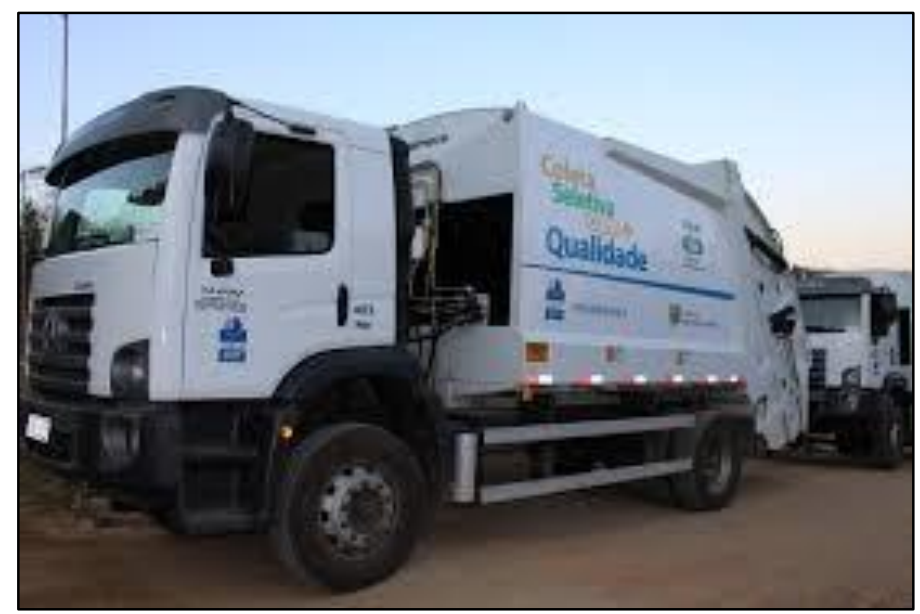

Figura 1. Compactador de lixo - São José dos Campos/SP

Segundo o Ministério do Meio Ambiente, a implantação da coleta seletiva é obrigação dos municípios e metas referentes à coleta seletiva fazem parte do conteúdo mínimo que deve constar nos planos de gestão integrada de resíduos sólidos dos municípios.

\subsection{Ponto de Entrega Voluntária (PEV)}

Existe outra possibilidade de descarte para esses resíduos, o Ponto de Entrega Voluntária (PEV) conforme Figura 2, que representam uma parte importante do sistema de gestão de resíduos, onde são recebidos diversos tipos de resíduos de pequenos geradores, são instalados em pontos estratégicos, com grande fluxo de pessoas e fácil acesso, inclusive para automóveis, são recebidos: restos de obras de construção, móveis e equipamentos domésticos, pilhas, baterias, lâmpadas, restos de poda, tinta, 


\section{ISSN $2447-5378$}

pneus e óleo de cozinha entre outros, que atende a determinação da Resolução Federal 307/2006, do CONAMA (Conselho Nacional do Meio Ambiente), e da Lei Municipal 7.146/2006 (BRASIL, 2006).

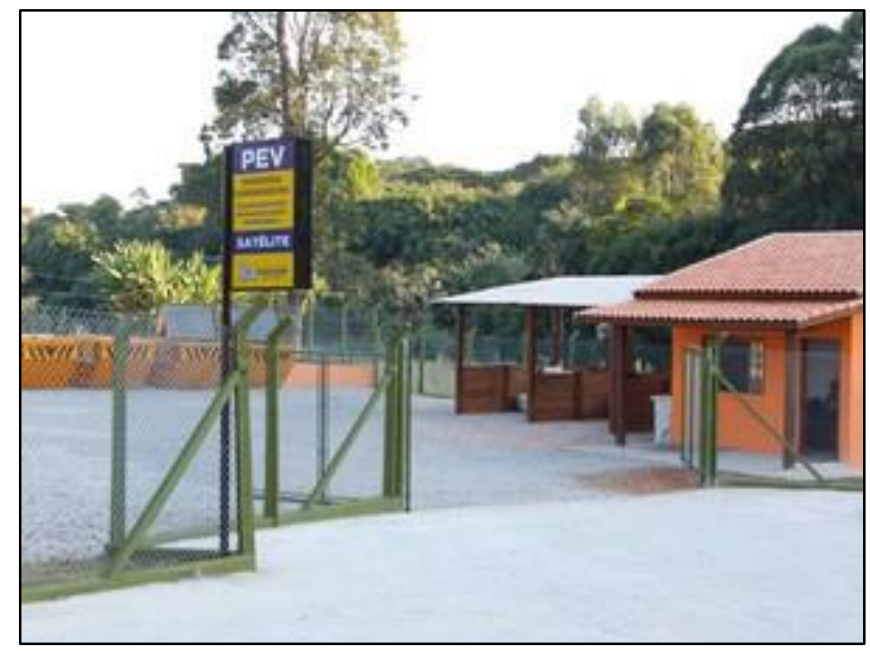

Figura 2. PEV em São José dos Campos/SP

São utilizadas cores para identificar os recipientes para o descarte de cada resíduo, conforme Figura 3, para papéis utiliza-se a cor azul, para o plástico utiliza-se a cor vermelha, para metais utilizase a cor amarela e para vidros a cor verde, de acordo com a Resolução CONAMA 275/01.

Nos Pontos de Entrega Voluntária não são recebidos resíduos orgânicos, cadáveres de animais, resíduos hospitalares e quantidades acima de $1 \mathrm{~m}^{3}$.

As empresas que geram muitos resíduos devem encaminhá-los para empresas recicladoras ou aterros privados licenciados e podem contratar empresas de caçambas para transportar esses resíduos.

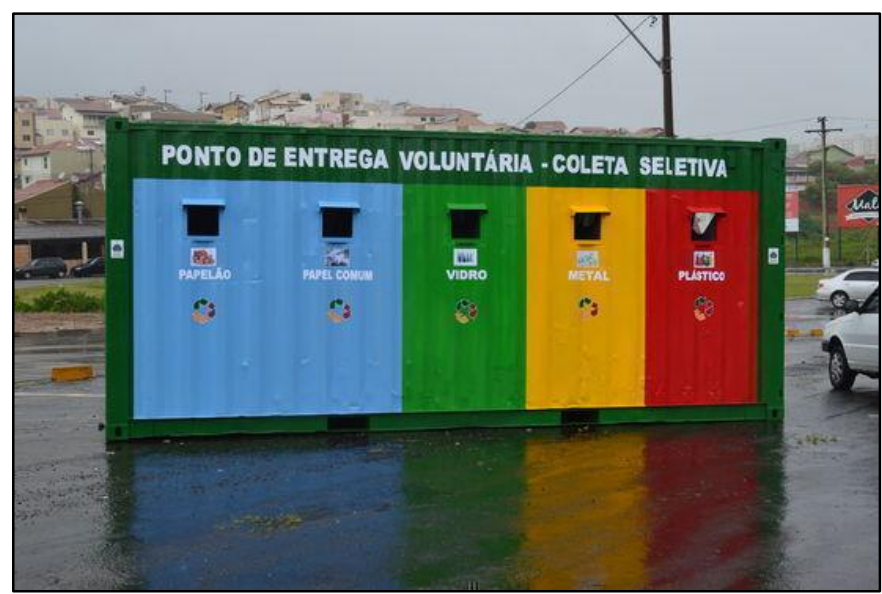

Figura 3. PEV separada por tipos de resíduos

\subsection{Logística reversa}

Outra alternativa para a população seria utilizar a política dos 3 R's, que significa Reutilização, Reaproveitamento e Reciclagem.

Com a reutilização as pessoas podem aproveitar um produto por mais tempo, com o reaproveitamento podem utilizá-lo de uma outra forma e com a reciclagem podem transformar o produto em outra coisa, para que os recursos sejam melhores reaproveitados e obtenham a recuperação de valor, destinando com segurança de forma correta o produto após o uso. 
A reciclagem na sua essência é uma forma de educar e fortalecer nas pessoas o vínculo afetivo com o meio ambiente, despertando o sentimento de empatia com o próximo e com o meio ambiente e poder modificar o meio em que vivem para melhor (CALDERONI, 1997).

A Figura 4, expõe a cadeia de suprimentos reversa onde exemplifica como é o ciclo de vida de um produto, começa com a matéria-prima, onde passa pelos fornecedores até serem fabricadas e vendidas, após o uso do consumidor torna-se resíduo, em seguida é feita a coleta seletiva onde os resíduos podem ser reciclados e dessa forma transformam-se em uma nova matéria-prima ao invés de ser enviada aos aterros sanitários.

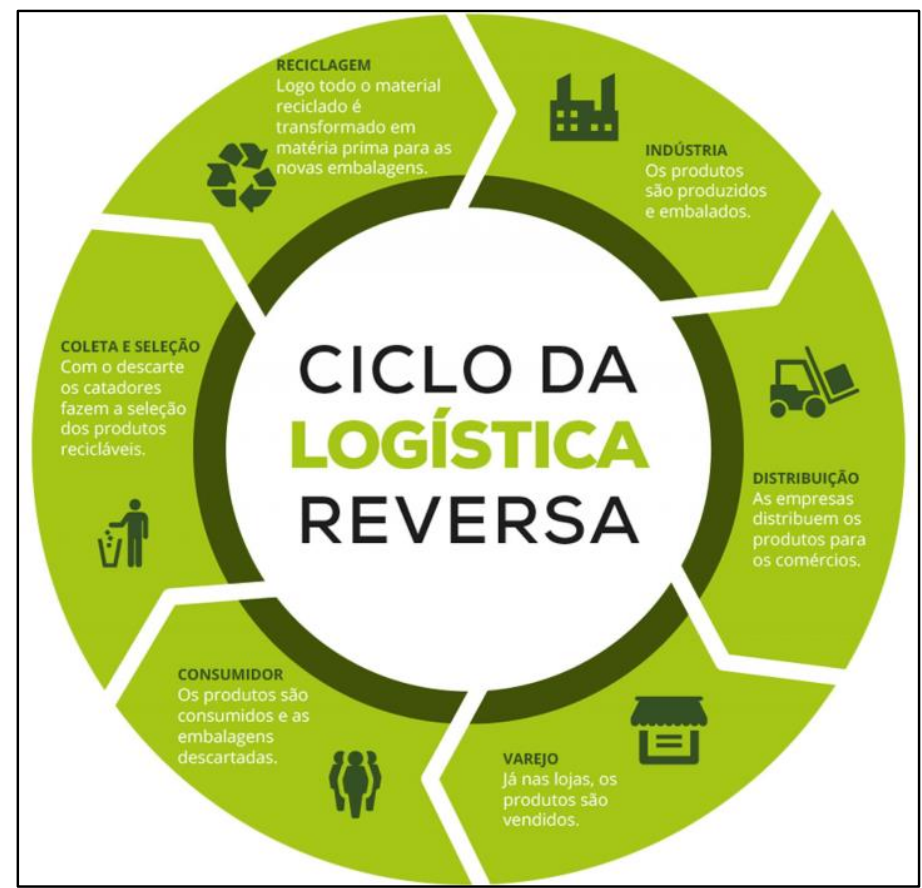

Figura 4. Cadeia de suprimentos e ciclos da logísticas reversa.

\subsection{Aterro Sanitário}

Segundo Albuquerque (2011), os aterros sanitários conforme Figura 5, são espaços a céu aberto e normalmente encontrados em locais distantes da população, no qual os lixos coletados e compactados são depositados e enterrados formando várias camadas para minimizar os impactos que o lixo provoca na natureza como contaminação de solo, ar e água.

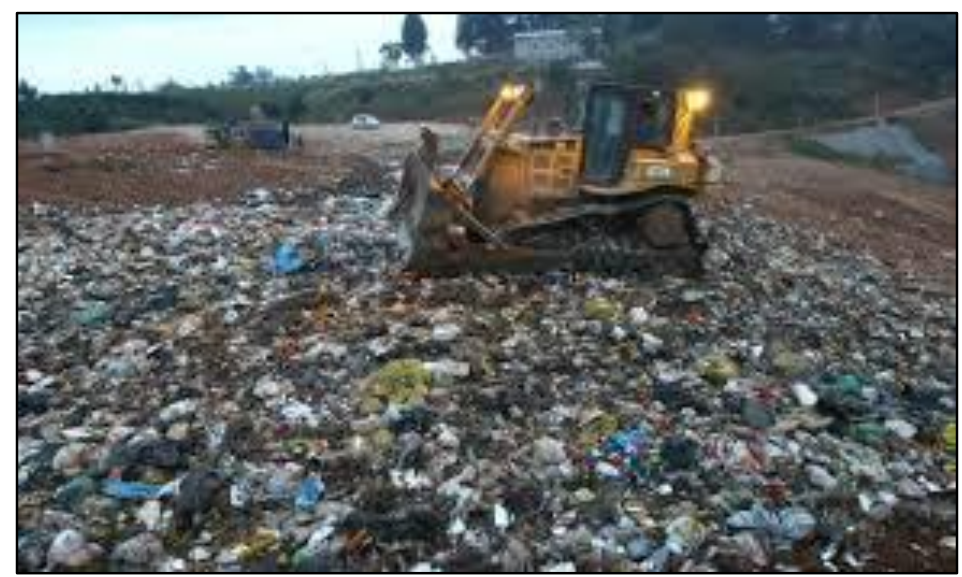

Figura 5. Aterro sanitário 
Quando os resíduos são recebidos nos aterros eles passam pelo espalhamento, compactação, a cobertura e drenagem dos resíduos. Ao final destes processos o lixo ficará protegido de espalhamento pelo vento e da ação de insetos e animais. Um aterro sanitário é definido como aterro de resíduos sólidos urbanos, ou seja, especialmente projetado para a recepção de resíduos de origem doméstica e comércios para que se reduza o perigo para a saúde e segurança da população (ALBUQUERQUE, 2011). ambientais.

Os aterros são um método de engenharia com uma técnica para minimizar os impactos

\begin{abstract}
Apresenta baixo custo operacional, se comparado às alternativas existentes, oportunizando a associação de outras tecnologias, além de ser uma amplamente conhecida, que potencializa a geração de empregos, permitindo também a possibilidade de gestão consorciada entre Municípios. Nesse caso, os custos podem ser reduzidos significativamente (COSTA E RIBEIRO, 2013, p.53).
\end{abstract}

Apesar de ter algumas vantagens os aterros também têm grandes desvantagens como odores característicos, a exposição de riscos aos trabalhadores, e ainda esses aterros se constituem em grandes fontes de emissão de gases de efeito estufa e havendo potenciais doenças associadas (COSTA e RIBEIRO, 2013).

\title{
3. MATERIAIS E MÉTODOS
}

Os procedimentos metodológicos utilizados nesta pesquisa foram por meio de investigação e coleta de dados através de mídias sociais, pesquisas bibliográficas, teses, dissertações, publicações em revistas eletrônicas, e por fim demonstrar como a logística reversa gera grande impacto no meio ambiente, com objetivo de desenvolver e contribuir de forma sustentável, além de solucionar problemas da comunidade.

\subsection{Tipo de pesquisa}

Foi utilizada uma pesquisa qualitativa e quantitativa, conforme Gressler (2003), a abordagem qualitativa é a formulação de hipóteses, definições operacionais de variáveis, quantificação nas modalidades nas coletas de dados e de informações. Na pesquisa quantitativa percebe-se que ela se difere da não utilização de instrumentos estatístico, mas busca descrever a complexidade de determinado problema não envolvendo manipulação de variáveis ou estudos experimentais.

\subsection{Meios de Investigação}

Os meios de investigação utilizados foram pesquisa bibliográfica, artigos científicos, aplicação de questionário pelo Google Forms, que foi compartilhado por mídias eletrônicas, para que voluntários aleatórios e de ambos os sexos pudessem responder online. O questionário "Benefício da logística reversa e coleta seletiva", foi respondido por 335 pessoas e seu objetivo era verificar e analisar o grau de conhecimento e consciência da população em relação a coleta seletiva e o descarte correto de resíduos.

\section{RESULTADOS E DISCUSSÕES}

Conforme o questionário realizado online pelo Google Forms do dia 13 a 21 de maio de 2019, por meio de 335 voluntários, para obter informações de como as pessoas descartam seus resíduos. Podemos observar na primeira questão "Você sabe o dia que passa o coletor de lixos recicláveis na 


\section{ISSN $2447-5378$}

sua rua durante a semana?" que $28,7 \%$ dos entrevistados não sabem os dias que os coletores de lixo reciclável passam em frente a sua residência, sendo assim, 71,3\% dos entrevistados têm acesso a esse tipo de informação conforme Gráfico 1.

\section{Gráfico 1. Estatística sobre os dias de coletas do lixo reciclável}

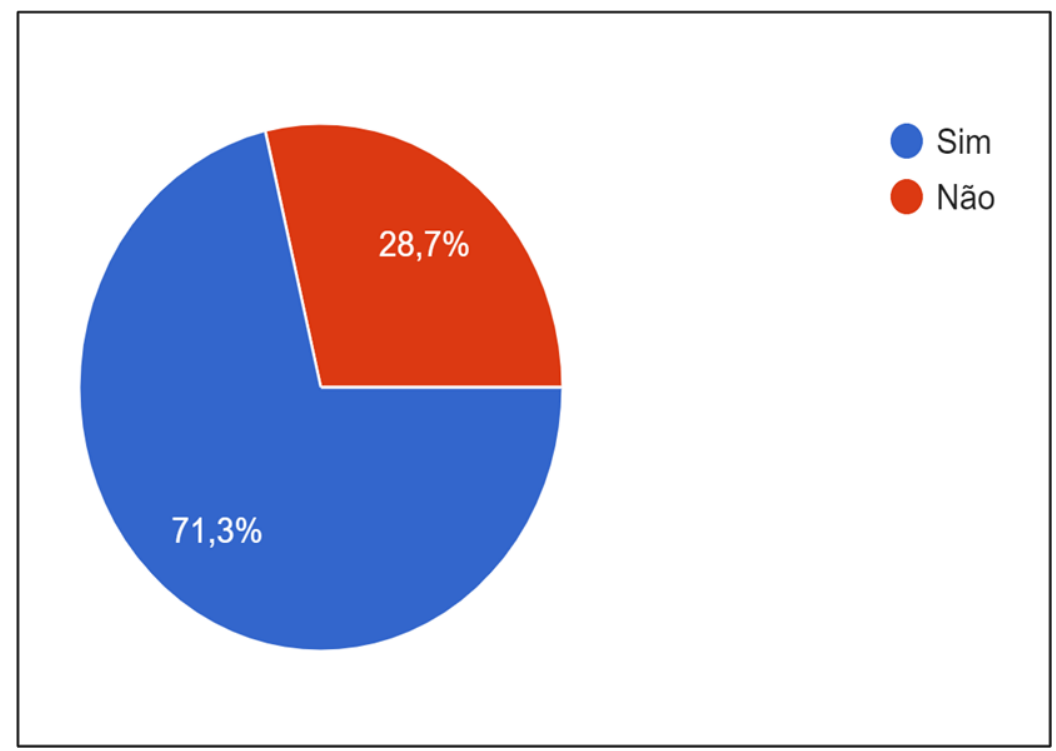

Na mesma pesquisa, mas agora para obtermos a informação em dados para saber a quantidade e porcentagem de pessoas que não fazem a devida separação dos lixos recicláveis e orgânicos para que seja possível notar a gravidade da situação, foi questionado aos entrevistados "Você descarta corretamente o lixo, separando os recicláveis do lixo orgânico?".

Foi obtido conforme o Gráfico 2 que aproximadamente $75,8 \%$ das pessoas fazem a devida separação e 24,2\% não fazem a separação correta.

Gráfico 2. Estatística sobre separação de lixos no descarte

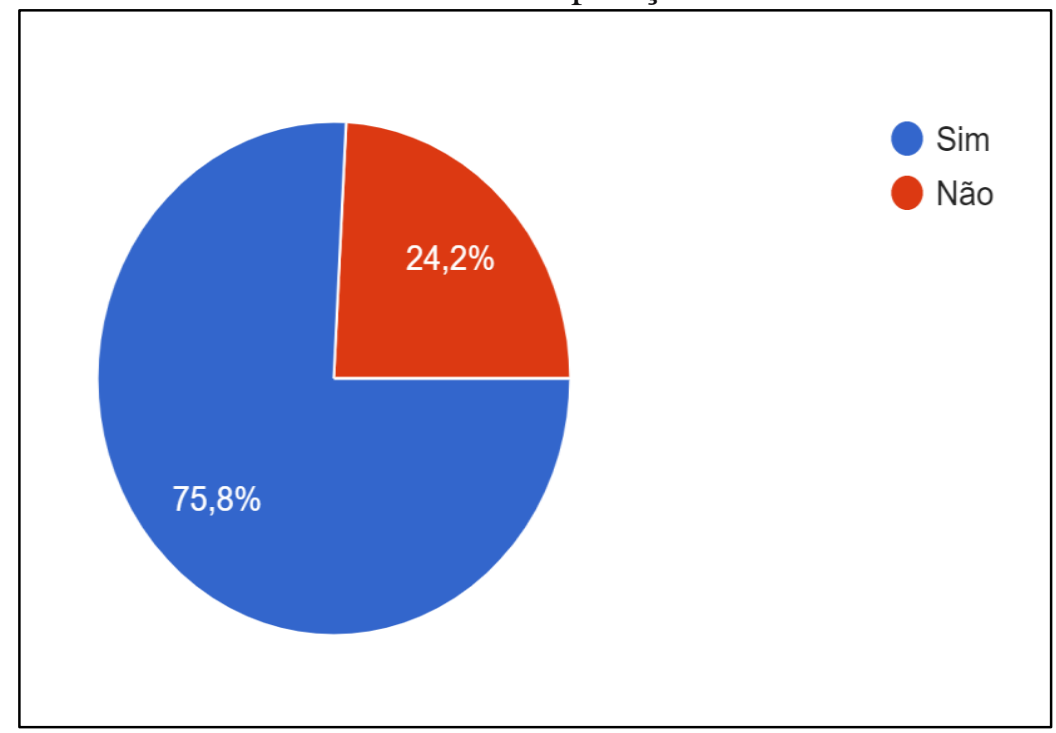

Na terceira questão da pesquisa "Você usa a PEV para descartar alguma coisa?" Considerando a PEV (Ponto de Entrega Voluntária) no qual o objetivo é evitar despejo de entulho em áreas impróprias e direcionar esse material para a reciclagem. 
Conforme a Gráfico 3 os resultados obtidos do questionamento foram que aproximadamente 66,8\% dos entrevistados fazem o uso da PEV para descarte de resíduos específicos e 33,2\% não fazem o uso da PEV.

Gráfico 3. Estatística sobre utilização de PEV

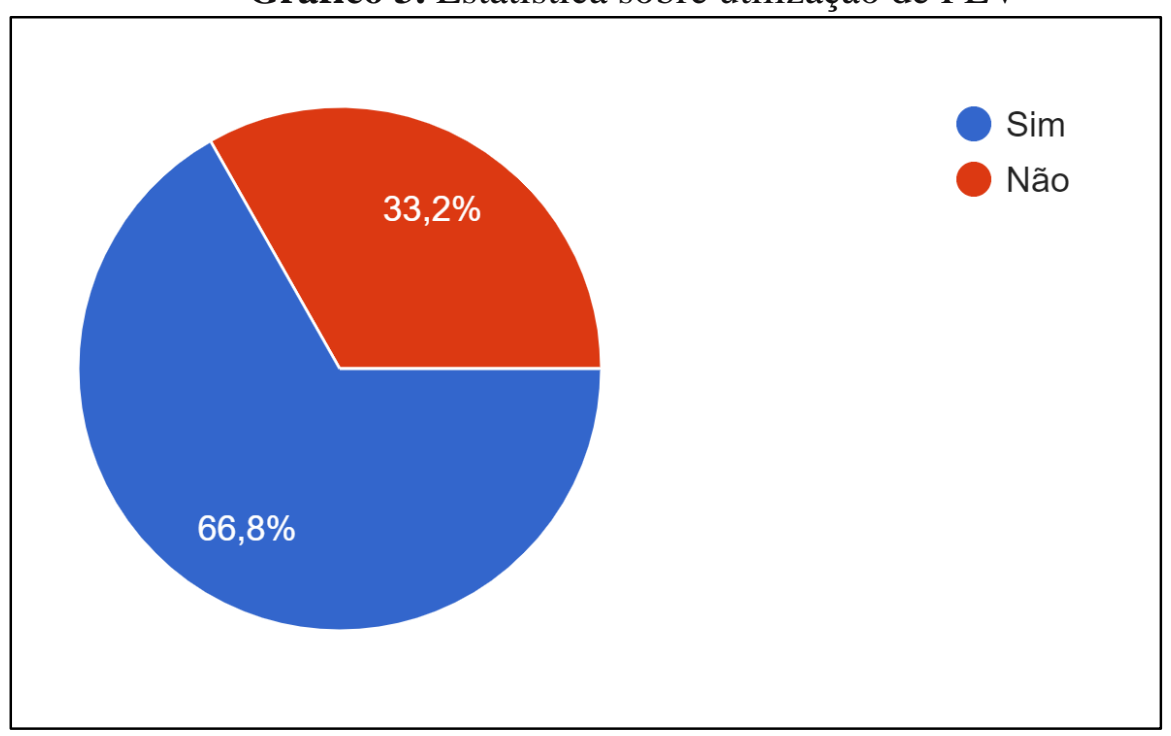

Segundo a Gráfico 4, é exposto o resultado da questão "Como você descarta seus eletroeletrônicos?” As opções foram lixo comum, lixo reciclável e outros. Na alternativa "outros" foi aberto para que pudessem informar a forma que descartam. Nesta última alternativa que obteve um percentual de $7,5 \%$ foram encontradas diversas respostas.

Conforme as respostas obtidas, foi constatado que grande parte dos entrevistados fazem um descarte devidamente correto, 63,8\% descartam em pontos de coletas, e muitos têm a preocupação de fazer um descarte ajudando outras pessoas, como os que responderam que entregam para pessoas que possam reutilizar peças e executar outras atividades com esses materiais.

Gráfico 4. Estatística sobre descarte de eletroeletrônicos

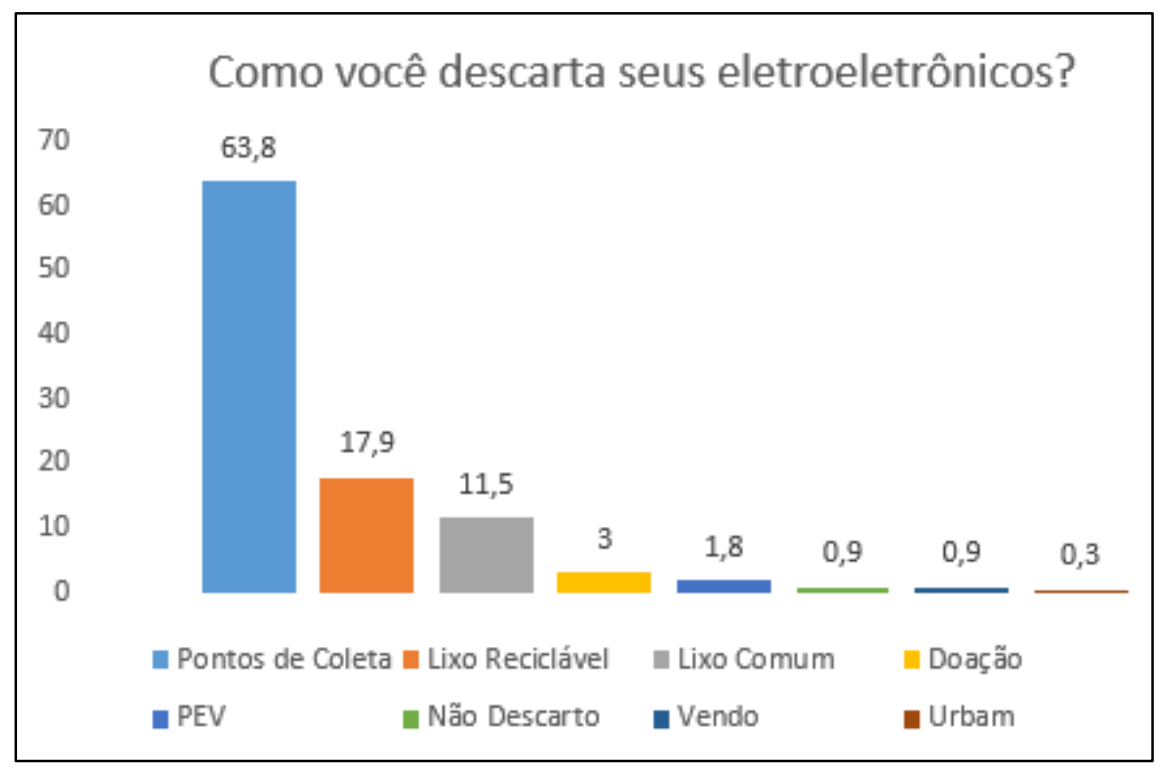




\section{CONSIDERAÇÕES FINAIS}

Conforme exposto neste trabalho, considera-se a importância da separação dos lixos e coleta seletiva para conciliar o crescimento econômico com responsabilidade, tanto social quanto ambiental, através da sustentabilidade. Com os resultados observados do questionário realizado em mídias sociais nota-se que muitas pessoas não sabem os dias que o caminhão de lixo passa em frente as suas residências, considerando que os coletores passam em média seis vezes na semana, conforme a necessidade de cada bairro, é um número relativamente alto de pessoas que não têm ou que não procuram esse tipo de informação, seja por descuido, falta de divulgação da prefeitura ou falta de preocupação com a importância da separação correta de seus lixos e que consequentemente prejudica a coleta seletiva. Sendo que essa informação pode ser acessada através do site da Urbanizadora Municipal de São José dos Campos, que por sua vez as pessoas podem consultar o dia e horário que são coletados os resíduos.

Após a comparação da primeira e segunda questão do questionário percebe-se que é diferente o percentual, que mais pessoas fazem a separação correta do que as pessoas que sabem os dias de coleta, isso se dá conforme informações obtidas de entrevistados que moram em condomínios, eles fazem a separação correta, porém não tem a necessidade de saber o dia que os coletores de lixos passam, pois, o lixo é depositado em local apropriado no condomínio onde é feita a coleta.

A coleta seletiva é a forma em que moradores e geradores de seus próprios resíduos destinem adequadamente os seus resíduos. E para que isso seja realmente efetivado é necessário palestras e campanhas para que as pessoas entendam a real necessidade de manter uma vida sustentável e que essa mudança pode trazer grandes benefícios tanto individualmente, quanto para a comunidade em geral, sendo assim, é importante que esse interesse comece pelas crianças, pois se forem orientadas concernente a seus hábitos, valores e atitudes relacionadas ao meio ambiente, poderão contribuir com mudanças ambientais significativas através da nova visão adquirida e repassar para os demais familiares.

\section{REFERÊNCIAS}

ALBUQUERQUE, J. B. (2011). Torres de resíduos sólidos. Leme: Independente, 2011.

BRAGA, J., S. S; RIZZO, M.R. (2010). Sustentabilidade através do aproveitamento de resíduos. Um estudo de processos implantados por um supermercado de médio porte. Revista Brasileira de Engenharia de Biossistemas, UNICAMP, 2010.

BRASIL. (2010). Lei 12.305/2010 - Política Nacional de Resíduos Sólidos - PNRS, Disponível em: http://www.planalto.gov.br/ccivil_03/_Ato2007-2010/2010/Lei/L12305.htm. Acesso em: 19/03/2019.

BRASIL. (2006). Ministério do Meio Ambiente (MMA). Conselho Nacional do Meio Ambiente (CONAMA). Lei Municipal 7.146/2006. Disponível em: https://www.mma.gov.br/estruturas/pnf/_arquivos/rs\%20conama\%20378_2006.pdf. Acesso em: 25/03/2019. 
BRASIL. (2012). Ministério do Meio Ambiente - Planos de gestão de resíduos sólidos: Manual de orientação Brasília. Disponível em:

https://www.mma.gov.br/estruturas/182/_arquivos/manual_de_residuos_solidos3003_182.pdf.

Acesso em: 22/08/2019.

CALDERONI, S. (1997). Os bilhões perdidos no lixo. São Paulo: Ed. Humanitas, 1997.

COSTA, B. S.; RIBEIRO, J. C. J. (2013). Gestão e gerenciamento de resíduos sólidos: direitos e deveres. Rio de Janeiro: Lumen Juris, 2013.

GRANDELLE, R. (2014). Preocupação da Sociedade com o Planeta leva Empresas a Investir em Projetos Sustentáveis. Disponível em: http://oglobo.globo.com/sociedade/sustentabilidade/preocupacao-da-sociedade-com-planeta-levaempresas-investir-em-projetos-sustentaveis-12723656. Acesso em: 11/03/2019.

GRESSLER, L. A. (2003). Introdução à pesquisa: projetos e relatórios. São Paulo: Loyola, 2003.

IBGE. (2008). INSTITUTO BRASILEIRO DE GEOGRAFIA E ESTATÍSTICA. Disponível em: https://www.ibge.gov.br/estatisticas/multidominio/meio-ambiente/9073-pesquisa-nacional-desaneamento-basico.html?=\&t=resultados. Acesso em: 26/08/2019.

LEITE, P. R. (2009). Logística reversa: meio ambiente e competitividade. São Paulo: Pearson Prentice Hall, 2009.

LIMA, L. M. Q. (1991). Tratamento do lixo. 2a edição revista. São Paulo: Hemus Editora Ltda.,1991.

MACEDO, R. L. G. (2000). Percepção e Conscientização ambientais. Lavras/MG: UFLA/FAEPE. 2000.

MOURA, L. A. A. (2011). Qualidade e gestão ambiental. Belo Horizonte: Del Rey, 2011.

PAOLESCHI, B. (2010). Logística Industrial Integrada do Planejamento, Produção, Custo e Qualidade à Satisfação do Cliente. 2a edição. São Paulo. Érica, 2010.

URBANIZADORA MUNICIPAL DE SÃO JOSÉ DOS CAMPOS. Disponível em: https://www.urbam.com.br/sitenovo/servicos/estacao-de-tratamento-de-residuos-solidos/aterrosanitario.aspx, Acesso em: 22/08/2019.

ZANTA, V. M; FERREIRA, C. F. A. (2003). Gerenciamento Integrado de Resíduos Sólidos Urbanos. In: Resíduos Sólidos Urbanos: Aterro Sustentável para municípios de pequeno porte. Rio de Janeiro. ABES, RIMA. p.1-16. 2003. 